\title{
Development of an oral anticoagulant-use attitude scale, and assessment of its validity and reliability
}

\author{
Ozlem Dogu, PhD, Nursan Cinar, PhD, Unal Erkorkmaz, PhD
}

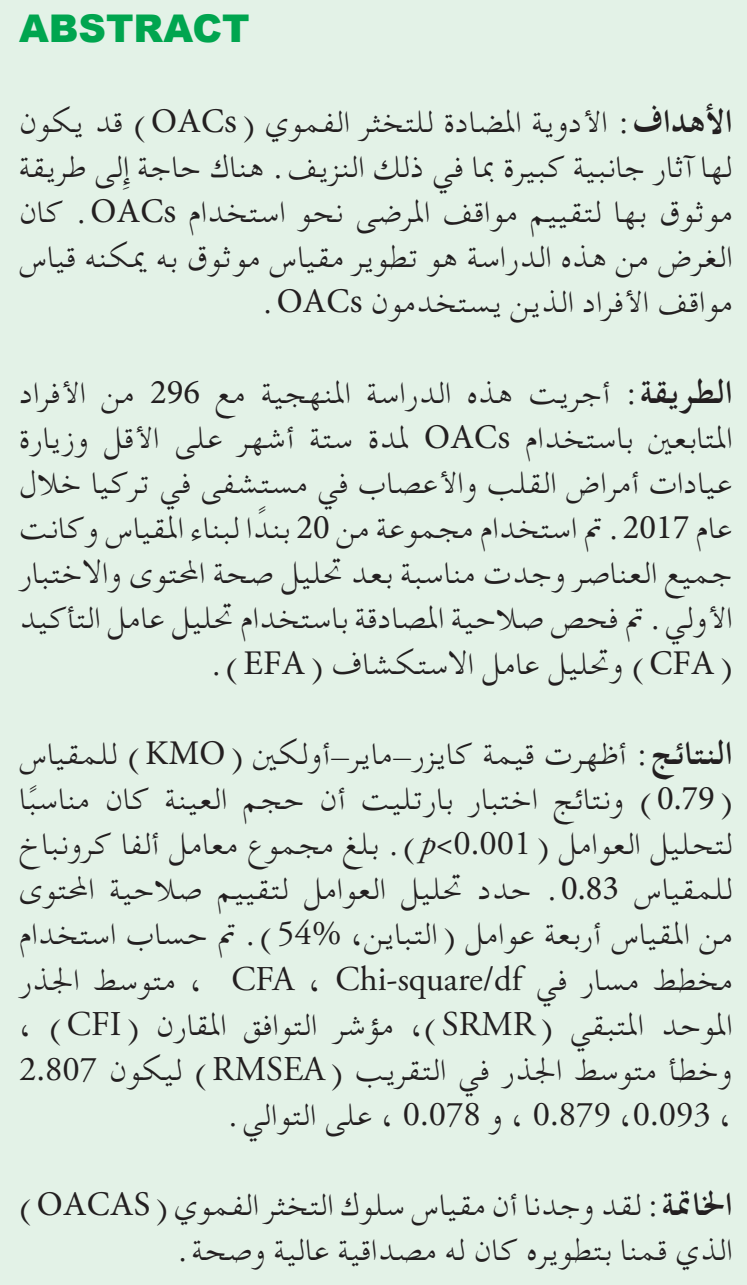

Objectives: To develop a reliable scale that can measure the attitudes of individuals using oral anticoagulant drugs (OACs).

Methods: This methodological study was conducted with 296 followed-up individuals using OACs for at least 6 months and visiting the cardiology and neurology clinics of a hospital in Turkey during 2017. A 20-item pool was used to construct the scale and all items were found suitable after content validity analysis and preliminary testing. Construct validity was examined using confirmatory factor analysis (CFA) and exploratory factor analysis (EFA).

Results: The Kaiser-Meyer-Olkin (KMO) value of the scale (0.79) and results of Bartlett's test showed that the sample size was suitable for factor analysis $(p<0.001)$. The total Cronbach alpha coefficient of the scale was 0.83 . Factor analysis to assess construct-content validity of the scale identified 4 factors (variance, $54 \%)$. Using a path diagram in CFA, Chi-square/df ratio values was calculated at 2.807 , standardized root mean square residual (SRMR) at 0.093 , comparative fit index (CFI) at 0.879 , and root mean square error of approximation (RMSEA) at 0.078 .

Conclusions: We found that the OACAs we developed had high reliability and validity.

Saudi Med J 2018; Vol. 39 (12): 1242-1248 doi: 10.15537/smj.2018.12.23138

From the Department of Fundamentals (Dogu), Department of Pediatric (Çinar), and the Department of Biostatistics (Erkorkmaz), Sakarya University, Sakarya, Turkey.

Received 3rd July 2018. Accepted 28th October 2018.

Address correspondence and reprint request to: Dr. Ozlem Dogu, Department of Fundamentals, Sakarya University, Sakarya, Turkey. E-mail: ozlemdogu@sakarya.edu.tr

ORCID: orcid.org/0000-0003-1257-2551

$\mathrm{V}$ arious drugs are used for the diagnosis and treatment of diseases in clinics and nurses have important responsibilities both in the administration of drugs and patient training. Educating individuals regarding safe drug use, especially with respect to increased drug use after discharge, has assumed increasing importance due to the increasing number of chronic diseases in recent 
years. ${ }^{1,2}$ Oral anticoagulant (OAC) drugs constitute a group of drugs that inhibit thrombus formation or thrombus growth in arteries and veins by disrupting the activity and synthesis of coagulation factors. Oral anticoagulant drugs taken orally attain the maximum blood level within 2-8 hours, with a half-life of 40-48 hours and physiological effects lasting for 5 days. ${ }^{1-4}$ Side effects of OAC drugs such as bleeding and clot formation occur frequently during long-term treatment of neurological and cardiovascular diseases. Narrow and variable therapeutic ranges, interactions with food and drug groups, and individual characteristics can lead to life-threatening problems during drug use. ${ }^{4-6}$

Jeffree et $\mathrm{al}^{7}$ reported that the most important side effect of OAC use is bleeding and vital problems can be experienced according to the severity of the bleeding. In the 1993-2006 study of the Adverse Evert Reporting System (AERS), ${ }^{8}$ it was reported that there were 9766 people in America who were registered to the emergency service due to bleeding, 8415 of them were using anticoagulants and 999 of died. ${ }^{7}$ Similarly, Serebruany et $\mathrm{al}^{8}$ reported that 128,267 drug deaths in the AERS were associated with 14,917 OACs reports. ${ }^{8}$ Piazza et $\mathrm{al}^{9}$ noted that $48 \%$ of adverse drug errors reported in a hospital between 2004 and 2009 were associated with anticoagulant. It was found to be limited studies on the subject in Turkey. Doğu \& Acaroğlu ${ }^{1}$ reported that $52.4 \%$ of individuals using OAC had experience of bleeding. As seen in the results of this study are significant side effects that cannot be ignored; bleeding risk in patients using oral anticoagulants. ${ }^{1}$

Mortality, due to the use of anticoagulants, decreases prevention of drug interactions and compliance with treatment. ${ }^{1,10}$ Health behaviors are the set of behaviors that an individual believes such as practices for the protection of health, the development of health, and the safe use of medicine. Oral anticoagulant in drug use behavior change is possible by informing the individual. There is a need to analyze factors that increase individuals' understanding of the above issues and ensure lasting behavior change. ${ }^{1,3,11,12}$ In the present study, the side effects of OAC medication are significantly higher. Therefore, determining the attitudes of individuals in using OACs is required for clarity and to identify deficiencies. Starting from this idea to determine the attitudes of individuals for using

Disclosure. Authors have no conflict of interests, and the work was not supported or funded by any drug company.
OAC is required so that we can emerge as clear and reveal the deficiencies. Keeping individuals informed about OAC drug use, developing appropriate and accessible solutions for patients to make necessary lifestyle changes, and safe drug use play an important role in the achievement of the expected therapeutic effect. The purpose of the present study was to develop a scale aimed at determining the attitudes of individuals towards OAC use and to support the educational content in this context.

Methods. This was a methodological study conducted to develop an oral anticoagulant-use attitude scale (OACAS) cross section and descriptive aimed at determining the attitudes of individuals towards oral anticoagulant treatment.

During the development of the scale, items were selected to reflect the goal of the scale accurately and the main points considered were consistency with literature, clarity, and comprehensibility of terms. A total of 20 scale items were presented to members of the faculty of neurology $(n=3)$, cardiology $(n=2)$, pharmacology (3), biochemistry $(n=1)$, nursing $(n=8)$, pharmaceutics $(n=2)$, Turkish language $(n=2)$, and of statistics $(n=1)$; their expert opinions were sought to determine whether the items were appropriate for the aim of the assessment, whether they represented the area of the assessment, and whether they include terms different than the intended ones. Content validity analyses were performed after the expert opinions were obtained. All the 20 items selected to determine attitudes towards OAC use were found to result in sufficient validity for the scale, with a Content Validity Index (CVI) value greater than 0.42 among 20 experts. The total content validity ratio of the scale was calculated as 0.79 .

The study was permitted by the management of the institutions where the study was conducted and approval was obtained from the Ethics Committee of Sakarya University, Sakarya, Turkey. Individuals who constituted the research sample were informed about the purpose and duration of the study, and the expectations from them. Informed consent to participate in the study was obtained.

The study group consisted of individuals $(n=296)$ who applied to the cardiology and neurology outpatient clinics of a single research and education hospital in the province of Sakarya, Turkey, between March and December 2017.

Inclusion criteria to the study were patients who used OAC drugs for 6 months and above, having at least 18 years of age, well competent in using Turkish language, and volunteering to participate. The exclusion 
criteria were patients who used OAC drugs for less than 6 months, having bad health condition, and have communication problem.

The data were collected 5 days a week at the outpatient clinic through a face to face interview with all volunteers during Tuesday and Thursday. In the literature, it is stated that the number of samples should be at least 10 times the scale item in scale development. ${ }^{13}$ This was taken into consideration in the number of samples. Test-retest analysis of the scale was performed with 20 individuals. The scale was evaluated with 20 individuals to assess comprehensibility by performing a preliminary study and unexplained expressions were edited.

Data were collected using a patient information form and the OACAS. The patient's information form was consisting 10 questions addressing sociodemographic information of the patients including age, gender, and education. Oral anticoagulant-use attitude scale is a 5-point Likert-type scale consisting of 20 items to tell how well a patient with OAC manages attitude. The item contents regarding how to manage attitude were designed specifically on OAC-use. The increase in the scale score showed that the attitude was positive and high. Participants were asked to read each statement in the scale and to respond based on whether or not they agreed with each item, by marking one of the options listed as following; 1) strongly disagree, 2) disagree, 3) undecided, 4) agree, 5) strongly agree. The maximum score in the scale was 100 and the minimum score was 20. it took approximately 10-15 minutes to fill.

Statistical analysis. Expert opinions were obtained and factor analysis was performed to assess the validity of the scale development; test-retest analysis and Cronbach alpha analysis were performed to assess reliability. Prior to factor analysis, the Kaiser-Meyer-Olkin (KMO) test and the Bartlett sphericity test, which evaluate correlation among the items were used to assess suitability of the data to the sample group and sample sufficiency. Construct validity was examined using exploratory factor analysis (EFA) and confirmatory factor analysis (CFA). The main factor constructs of the scale were evaluated using EFA; information regarding quality of the factors determined, general construction of the scale, and the extent to which the scale represented attitude towards $\mathrm{OAC}$ use were evaluated via CFA. Confirmatory factor analysis was performed using AMOS (IBM SPSS AMOS, Version 23.0. Armonk, NY: IBM Corp.)

Descriptive analyses were performed to provide information on general characteristics of the study population. The Kolmogorov-Smirnov test was used to evaluate whether the distribution of scales was normal and all scales were found to display a normal distribution.
Pearson's correlation coefficients were calculated to assess correlation between test-retest total scores of the scales, separately for subscales. The scales were represented as mean \pm standard deviation. A $p<0.05$ was considered significant. Analyses were performed using commercially available software (IBM SPSS Statistics, Version 23.0. Armonk, NY: IBM Corp.)

Results. Findings related to the study of scale development were examined under the headings of sociodemographic characteristics, KMO for validity and exploratory and confirmatory factor analysis, test-retest for reliability, correlation-based item analysis, and internal consistency analysis.

It was found that of the individuals, $53 \%$ were over 65 years old, $54.4 \%$ were male, $82.8 \%$ were married, $31.8 \%$ were secondary school graduates, $76 \%$ were not employed, and $50.7 \%$ had income equal to expenses. It was further determined that $58.4 \%$ had a heart disease, $41.6 \%$ used OAC due to a neurological disorder, and nearly half $(46.6 \%)$ had another chronic disease.

Construct validity. The scale was tested using EFA and CFA. In the first stage of the factor analysis, the suitability of the data obtained from preliminary application of the scale for factor analysis was tested using KMO and Bartlett's tests. The KMO coefficient was found to be 0.795 , and the Chi-square value obtained from Bartlett's test was found to be significant at the advanced level $\left(\chi^{2}=2566.27 ; p<0.001\right)$. The sample size was found to be suitable and sufficient for factor analysis.

Exploratory factor analysis. This was performed for the data set to evaluate construct validity of the scale and to determine and assess factor loads of the items in the scale. Based on the analysis, the scale was reduced to 4 subscales because 4 factors were found to have an eigenvalue greater than one (Figure 1). The total varianceexplaining ratio for the 7-item first sub-dimension (attitude towards safe environment and food interaction [SE]) was calculated to be $25.5 \%$, with $12.93 \%$ for the 3-item; 2nd sub-dimension (attitude toward safe medication $[\mathrm{SM}]), 9.1 \%$ for the 5 -item; 3rd sub-dimension (prevention of trauma and attitudes appropriate approach $[\mathrm{PT}]$ ), and $6.9 \%$ for the 5-item; 4th sub-dimension (attitudes toward the prevention of potential $[\mathrm{PR}]$ ); the total variance-explaining ratio of all the 4 sub-dimensions was calculated to be $54.37 \%$ (Table 1).

Confirmatory factor analysis. In the final stage, the fit indices were examined using the CFA model, which was formed as a 4-sub-dimension model. The 4-factor construct of the scale consisting of 20 terms showed 
good suitability. In order to verify the construct validity of the scale, a path diagram (Figure 2) was drawn based on CFA and the fit indices were calculated. Based on this, Chi-square $\left(\chi^{2}\right) /$ degrees of freedom $(\mathrm{df})$ were calculated to be 2.807 , standardized root mean square residual (SRMR) to be 0.093 , adjusted goodness of fit index (AGFI) to be 0.854 , comparative fit index (CFI) to

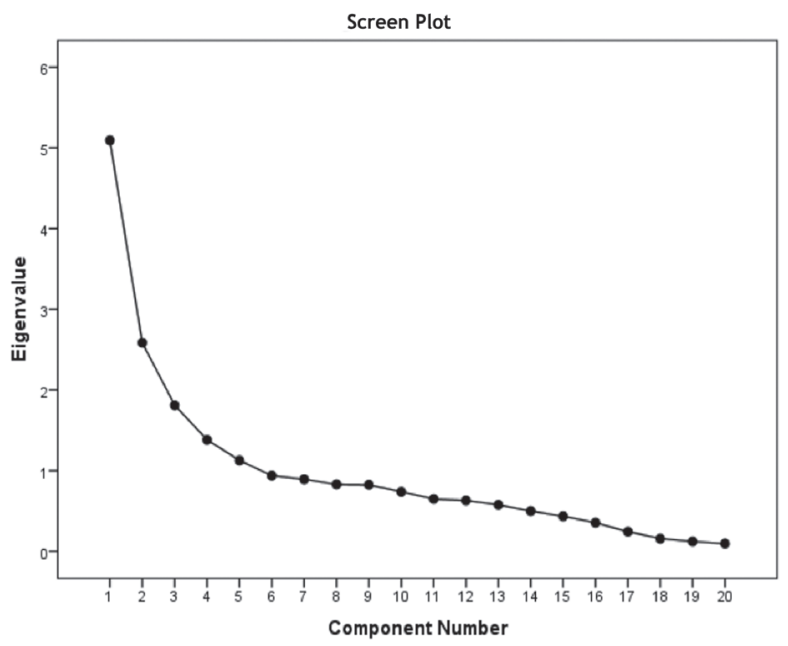

Figure 1 - Screen plot and eigenvalue of exploratory factor analysis. be 0.879 , and root mean square error of approximation (RMSEA) to be 0.078 (Table 2).

Scale reliability. Scale reliability was evaluated using internal consistency (Cronbach alpha) and test-retest methods.

Internal consistency (Cronbach alpha) reliability. Cronbach alpha reliability coefficients were calculated to assess whether the items involved in each factor in the scale measured the relevant factor and therefore whether all the items included in the scale measured the desired characteristic. The Cronbach alpha coefficients were calculated to be 0.841 for the first sub-dimension (SE), 0.937 for the 2 nd sub-dimension (SM), 0.617 for the 3rd sub-dimension (PR), and 0.641 for 4 th subdimension (PT). The Cronbach alpha coefficient for the entire scale was calculated to be 0.838 , and the scale was therefore considered reliable (Table 1).

Test-retest reliability. To determine reliability of the scale over time, test-retest analysis was performed by asking 20 individuals to fill in the scale again after 15 days. To assess the relationship between the scores obtained from the scale items and the total score, correlation-based item analysis was performed for all the items. When scale reliability was evaluated using test-retest analysis, a statistically significant consistency between the 2 measurements $(p>0.05)$

Table 1 - The results of factor analysis, item factor loads and internal consistency analysis of the OACAS.

\begin{tabular}{|c|c|c|c|c|c|}
\hline Dimensions & Items & Factor loads & $\begin{array}{l}\text { Corrected } \\
\text { item-total } \\
\text { correlation }\end{array}$ & $\begin{array}{l}\text { Cronbach's } \\
\text { alpha if } \\
\text { item deleted }\end{array}$ & $\begin{array}{c}\text { Cronbach } \\
\text { alpha }\end{array}$ \\
\hline \multirow{7}{*}{$\begin{array}{l}\text { Attitude towards safe } \\
\text { environment and food } \\
\text { Interaction }\end{array}$} & OACAS01 & 0.856 & 0.768 & 0.790 & \multirow[t]{7}{*}{0.841} \\
\hline & OACAS02 & 0.839 & 0.739 & 0.796 & \\
\hline & OACAS03 & 0.716 & 0.625 & 0.815 & \\
\hline & OACAS04 & 0.687 & 0.577 & 0.824 & \\
\hline & OACAS05 & 0.640 & 0.551 & 0.826 & \\
\hline & OACAS06 & 0.600 & 0.541 & 0.828 & \\
\hline & OACAS07 & 0.475 & 0.360 & 0.849 & \\
\hline \multirow{3}{*}{$\begin{array}{l}\text { Attitude toward safe } \\
\text { sedication }\end{array}$} & OACAS08 & 0.907 & 0.856 & 0.919 & \multirow[t]{3}{*}{0.937} \\
\hline & OACAS09 & 0.906 & 0.889 & 0.892 & \\
\hline & OACAS 10 & 0.863 & 0.864 & 0.912 & \\
\hline \multirow{5}{*}{$\begin{array}{l}\text { Prevention of } \\
\text { trauma and attitudes } \\
\text { appropriate approach }\end{array}$} & OACAS11 & 0.853 & 0.424 & 0.539 & \multirow[t]{5}{*}{0.617} \\
\hline & OACAS12 & 0.850 & 0.403 & 0.545 & \\
\hline & OACAS13 & 0.458 & 0.379 & 0.558 & \\
\hline & OACAS14 & 0.425 & 0.367 & 0.564 & \\
\hline & OACAS15 & 0.414 & 0.295 & 0.606 & \\
\hline \multirow{5}{*}{$\begin{array}{l}\text { Attitudes toward the } \\
\text { prevention of potential } \\
\text { risks }\end{array}$} & OACAS16 & 0.667 & 0.536 & 0.533 & \multirow[t]{5}{*}{0.641} \\
\hline & OACAS17 & 0.657 & 0.548 & 0.515 & \\
\hline & OACAS18 & 0.588 & 0.348 & 0.621 & \\
\hline & OACAS19 & 0.559 & 0.282 & 0.636 & \\
\hline & OACAS20 & 0.540 & 0.322 & 0.630 & \\
\hline \multicolumn{2}{|c|}{ Total variance-explaining ratio } & \multicolumn{3}{|c|}{$54.369 \%$} & \\
\hline
\end{tabular}


Table 2 - Fit indices, calculated by confirmatory factor analysis.

\begin{tabular}{lcc}
\hline Fit Indices & Referans values $e^{1,13}$ & Value \\
\hline$\chi^{2} / \mathrm{df}$ & $\leq 0 \mathrm{x}^{2} / \mathrm{df}<3^{9}$ & 2.807 \\
Standardized root mean square residual (SRMR) & SRMR $\leq 0.1^{2,4,7,15}$ & 0.093 \\
Goodness-of-fit index (GFI) & $\leq 0.90 \mathrm{GFI} \leq 0.95$ & 0.854 \\
Adjusted goodness of fit index (AGFI) & $\leq 0.85 \mathrm{AGFI} \leq 0.90^{3,6,7}$ & 0.813 \\
Root mean square residual (RMR) & $\mathrm{RMR} \leq 1^{2,6}$ & 0.156 \\
Incremental fit index (IFI) & $\mathrm{IFI} \geq 0.90^{5}$ & 0.880 \\
Normed fit index (NFI) & $\leq 0.90 \mathrm{NFI} \leq 0.95^{4,14}$ & 0.825 \\
Parsimonious goodness of fit index (PGFI) & PGFI $\geq 0.50^{6}$ & 0.667 \\
Parsimony normed fit index (PNFI) & PNFI $\geq 0.50^{6}$ & 0.712 \\
Root mean square error of approximation (RMSEA) & $\leq 0.05 \mathrm{RMSEA} \leq 0.08^{2,4,7,15}$ & 0.078 \\
Comparative fit index (CFI) & $\leq 0.95 \mathrm{CFI} \leq 0.97^{2,6}$ & 0.879 \\
\hline \multicolumn{2}{c}{$\chi^{2} / \mathrm{df}$ - Chi-square/degrees of freedom } \\
\hline
\end{tabular}

was found. The correlation $(r)$ between the first and second measurement scores of the scale was found to be statistically significant (Table 3 ). The total average OAC scale score was calculated to be $47.39 \pm 12.78$. The total sub-dimension scores of the scale were $20.08 \pm 7.22$ for SE, $7.64 \pm 4.46$ for SM, $9.95 \pm 3.34$ for PT, and $9.70 \pm 3.38$ for PR (Table 4).

The results of the correlation analysis to identify the relationship between the total score and sub-dimension scores of the scale are shown in Table 5. In general, it was found that all sub-dimensions had a statistically significant relationship with each other and with the total scale dimension, with the exception of the relationship between the SE sub-dimension and the PR sub-dimension which was not significant.

Discussion. In the present study, a 20-item OACAS consisting of 4 sub-dimensions comprising SE, SM, PT, and PR was developed to determine the attitudes of individuals towards OAC use. The scale was found to be valid and reliable, and to have sufficient psychometric properties.

The safe use of oral anticoagulant drugs and the satisfaction of the individual in this regard affect attitude towards drug use. Due to the frequent side effects and the narrow therapeutic range of OACs, patient attitude is one of the issues that need to be emphasized in Turkey as well as in other parts of the world. Individuals who receive OACs are expected to gain a positive attitude and become familiar with the drug use. Through the scale we developed, appropriate management of drug use and areas requiring training or information can be assessed easily. No significant difference was expected between measurements performed days apart, and this was found to be the case. Analyses performed to assess reliability of the scale revealed no change in the parameters with
Table 3 - Test-retest assessment for oral anticoagulant-use attitude scale.

\begin{tabular}{lrrrc}
\hline $\begin{array}{l}\text { OACAS } \\
\text { dimensions }\end{array}$ & $\begin{array}{c}\text { Pre-test } \\
(\mathbf{n}=\mathbf{2 0})\end{array}$ & $\begin{array}{c}\text { Post-test } \\
(\mathbf{n}=20)\end{array}$ & r & $P$-value \\
\hline SE & $27.35 \pm 4.61$ & $26.45 \pm 4.80$ & 0.913 & $<0.001$ \\
SM & $8.75 \pm 5.83$ & $8.55 \pm 5.64$ & 0.993 & $<0.001$ \\
PT & $9.95 \pm 3.10$ & $9.90 \pm 3.09$ & 0.997 & $<0.001$ \\
PR & $8.65 \pm 2.06$ & $8.70 \pm 2.11$ & 0.994 & $<0.001$ \\
Total & $54.70 \pm 8.71$ & $53.60 \pm 8.59$ & $\mathbf{0 . 9 6 7}$ & $<0.001$ \\
\hline \multicolumn{5}{c}{ OACAS - oral anticoagulant-use attitude scale, $r$ - correlation, } \\
SE - attitude towards safe environment and food interaction, \\
SM - attitude toward safe medication, PT - prevention of trauma and \\
attitudes appropriate approach, PR - attitudes toward the prevention of \\
potential risks \\
\hline \multicolumn{5}{c}{} \\
\hline \multicolumn{5}{c}{}
\end{tabular}

Table 4 - Sub-dimensions and total score averages of oral anticoagulantuse attitude scale $(\mathrm{n}=296)$.

\begin{tabular}{|c|c|c|c|}
\hline Sub-dimensions & $\begin{array}{c}\text { Median } \\
(\mathrm{IQR})\end{array}$ & Mean \pm SD & Min-max \\
\hline SE & $21(12)$ & $20.08 \pm 7.22$ & $7-33$ \\
\hline SM & $6 \quad(8)$ & $7.64 \pm 4.46$ & $3-15$ \\
\hline PT & $10(5)$ & $9.95 \pm 3.34$ & $5-21$ \\
\hline PR & $9 \quad(5)$ & $9.70 \pm 3.38$ & $5-21$ \\
\hline OACAS & $48(19)$ & $47.39 \pm 12.78$ & 20-82 \\
\hline \multicolumn{4}{|c|}{$\begin{array}{l}\text { IQR - interquartile range, OACAS - oral anticoagulant-use attitude } \\
\text { scale, SE - attitude towards safe environment and food interaction, } \\
\text { SM - attitude toward safe medication, PT - prevention of trauma and } \\
\text { attitudes appropriate approach, PR - attitudes toward the prevention of } \\
\text { potential risks }\end{array}$} \\
\hline
\end{tabular}

Table 5 - Pearson's correlation coefficient between OACAS total score and sub-dimension scores.

\begin{tabular}{llccc}
\hline & SE & SM & PT & PR \\
\hline SM & $0.426^{*}$ & 1 & - & - \\
PT & $0.297^{*}$ & $0.249^{*}$ & 1 & - \\
PR & 0.087 & $0.237^{*}$ & $0.355^{*}$ & 1 \\
Total OAC & $\mathbf{0 . 8 1 4 ^ { * }}$ & $\mathbf{0 . 7 1 8 ^ { * }}$ & $\mathbf{0 . 6 1 0 ^ { * }}$ & $\mathbf{0 . 4 8 9 *}$ \\
\hline
\end{tabular}

OACAS - oral anticoagulant, SE - attitude towards safe environment and food interaction, SM - attitude toward safe medication,

PT - prevention of trauma and attitudes appropriate approach, PR - attitudes toward the prevention of potential risks 


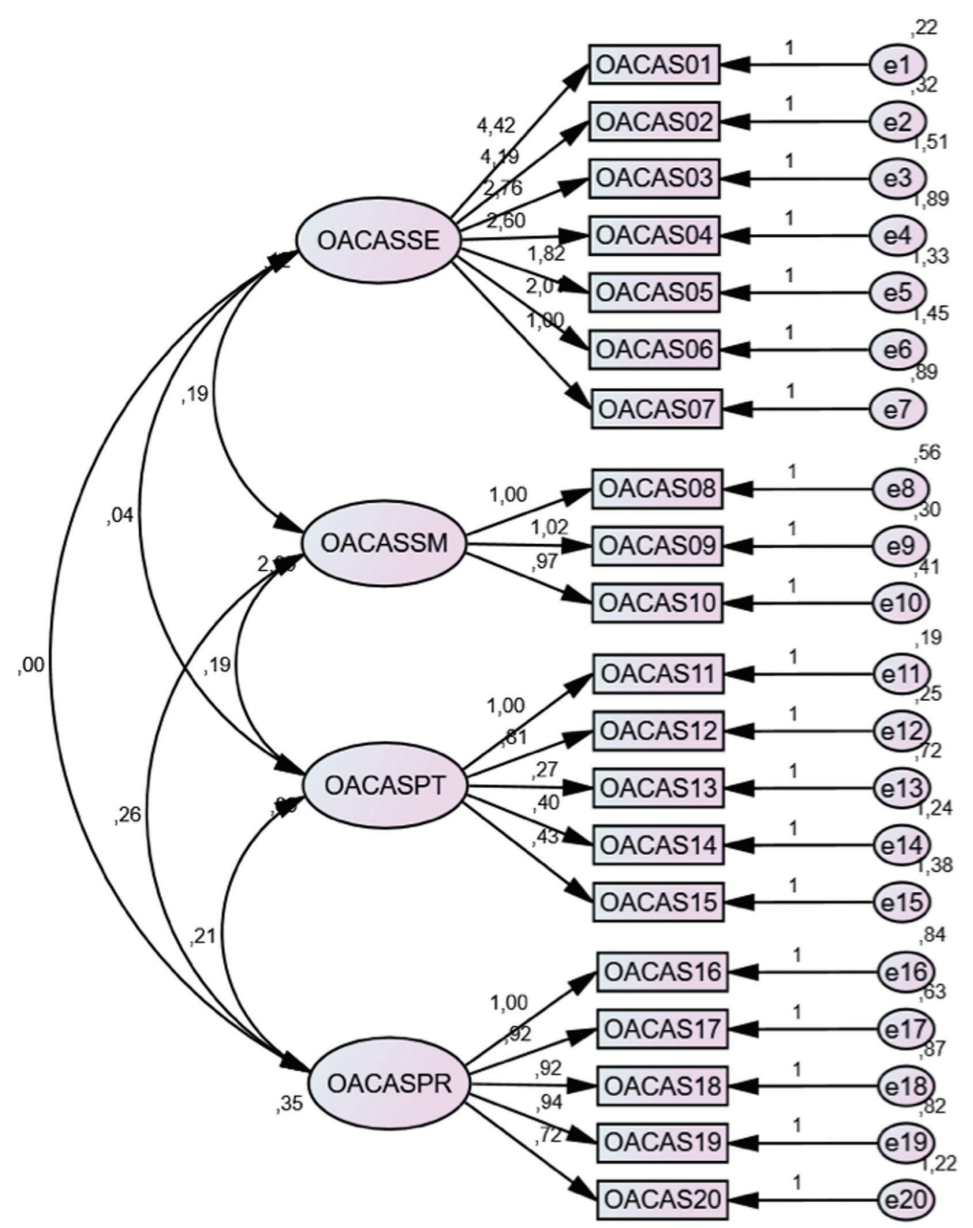

Figure 2 - Path diagram of oral anticoagulant-use attitude scale. OACAS - oral anticoagulant-use attitude scale.

time. In the factor analysis, the variance loads and each sub-dimension formed were evaluated in terms of item sub-dimension total score correlations. Four subdimensions with similar properties were obtained as a result of the varimax rotation of the 20-item scale.

The fact that the fit indices calculated in the frame of confirmatory factor analysis, especially the chi-square/ degrees of freedom were lower than three, the fact that the SRMR value was lower than 0.1 , and the fact that the RMSEA was lower than 0.08 indicated that the scale was suitable at an acceptable level. ${ }^{14-20}$ Because the Cronbach's alpha coefficients for the total scale and subdimensions of the scale were sufficiently good level, half of the variance was explained $(54.36 \%)$ and the scale could be considered valid and reliable. This indicated that the correlation between the items constituting the sub-dimensions and the theoretical structure of the subdimension was significant. The fact that the item-total score was positive and sufficiently high indicated that the items were suitable and consistent with each other. ${ }^{21-23}$

The time OAC use and age of participants (0-6 mounts) was a limiting factor, because certain OACAS questions were used for determination attitude development those between the ages of above 18 years. Although there are limitations, the sample was derived from a representative sample of the Sakarya-Turkey population. In the literature, we have not encountered with no assessment instrument evaluating attitudes of individuals toward OAC use and considering from this point of view, it will be the first relevant scale in literature. Attitudes are important when individuals use OAC medicines, which can have life-threatening problems, while maintaining compliance with care and providing health behaviors. With the developed scale, it will be possible to determine the current attitude and in this direction the needs of the individual will be 
revealed. Health professionals will support the creation of educational content that they will prepare for safe use of the drug and behavior modification.

It is proposed that the OAC use scale developed in the present study is valid and reliable for the Turkish population, that it can be used to determine attitudes towards drug use in individuals using OACs in clinics and in the public health area, and that it can also be used in studies addressing this topic comparing different groups. Further, the scale can be applied in international studies via language and community-based adaptation.

Acknowledgment. We would like to thank editing services Wordvice Editor for English language editing.

\section{References}

1. Doğu Ö, Acaroğlu R. Evaluatıon of medıcatıon management safety in patients using oral anticoagulants. Journal of Anatolia Nursing And Health Scuences 2016; 19: 152-158.

2. Craven RF, Hirnl CJ. Fundementals of Nursing Human Health and Function. 7th ed. Philedelphia (PA): Lippincott Company; 2017.

3. Rose AE, Robinson EN, Premo JA, Hauschild LJ, Trapskin PJ, Mcbride AM. Improving warfariin management within the medical home: a health-system approach. The American Journal of Medicine 2017; 130: 365.e7-365.e12.

4. Sharifi M, Vajo Z, Freeman W, Bay C, Sharifi M, Schwartz F. Transforming and simplifying the treatment of pulmonary embolism: "Safe dose" thrombolysis plus new oral anticoagulants. Lung 2015;193: 369-377.

5. Damme SV, Deyk KV, Budts W, Verhamme P, Moons P. Patient knowledge of and adherence to oral anticoagulation therapy after mechanical heart-valve replacement for congenital or acquired valve defects. Heart Lung 2011; 40: 139-146.

6. Shawa JR, Castellucci L, Siegal D, Stiell I, Syed S, Lampron J, et al. Management of direct oral anticoagulant associated bleeding: Results of a multinational survey. Thrombosis Research 2018; 163: 19-21.

7. Jeffree RL, Gordon DH, Sivasubramaniam R, Chapman A. Warfarin related intracranial haemorrhage: A case-controlled study of anticoagulation monitoring prior to spontaneous subdural or intracerebral haemorrhage. Journal of Clinical Neuroscience 2009; 16: 882-885
8. Serebruary V, Cherepanov V, Fortmann S, Hyun Kim M. Mortality and oral anticoagulants in the Food and Drug Administration Adverse Event Reporting System. Open Heart 2017; 4: e000629.

9. Piazza G, Nguyen TN, Cios D, Labreche M, Hohlfelder B, Faniko J, et al. Anticoagulation-associated adverse drug events. American Journal Medical 2011; 124: 1136-1142.

10. Wysowski DK, Nourjah P, Swartz L. Bleeding complications with warfarin use. Arch Intern Med 2007; 167: 1414-1419.

11. Siebenhofer A, Jeitler K, Horvath K, Habacher W, Schmidt L, Semlitsch T. Self-management of oral anticoagulation. Dtsch Arztebl Int 2014; 111: 83-9.

12. Piran S, Schulman S, Panju M, Pai M. Oral anticoagulant dosing, administration and storage: a cross-sectional survey of Canada health care providers. J Thromb Thrombolysis 2018; 45 : 180-185.

13. Büyüköztürk Ş. Sosyal Bilimler İçin Veri Analizi El Kitabı. 9. Baskı. Ankara: Pegem Yayınevi; 2008. p. 167-171.

14. Erkorkmaz Ü, Etikan İ, Demir O, Özdamar K, Sanisoğlu Y. Confirmatory factor analysis and fit indices: Review. Türkiye Klinikleri Journal Of Medical Science 2013; 33: 210-223.

15. Kline RB. Hypothesis Testing. In: Kenny DA, Little TD, editors. Principles and practice of structural equation modeling. 3rd ed. New York, The Guilford Press, 2011.p. 189

16. Byrne BM. Testing for the factorial validity of a theoretical construct. Structural equation modeling with AMOS: Basic concepts, applications, and programming. 2nd ed. New York (NY): Routledge; 2010. p. 74-82.

17. Vieira AL. Preparation of the analysis. Interactive LISREL in Practice. 1st ed. London (UK): Springer, 2011. p. 9-25.

18. Kelloway EK. Using Lisrel for Structural Equation Modeling. Assessing Model Fit. 3rd ed. United States of America: Sage Publications; 1998. p. 18-56.

19. Jöreskog KG, Sörbom D. Structural Equation Modeling with the SIMPLIS Command Language. 1st ed. USA, 1993.

20. Browne MW, Cudeck R. Single sample cross-validation indexes for covariance-structures. Multivar Behav Res 1989; 24:445-455.

21. Loehlin JC editors. Latent Variable Models. 4th ed. New Jersey: Lawrence Erlbaum Associations; 2004.

22. Özdamar K. Paket Programlar İle İstatistiksel Veri Analizi. Skın 2nd ed. Nisan: Kitabevi; 2018.

23. Alpar R. Uygulamalı Çok Değişkenli İstatistiksel Yöntemler, Detay Yayıncılık, 5th ed. Baskı: Ankara; 2017. 